\title{
2019 Novel Coronavirus Infection: Gastrointestinal Manifestations
}

\author{
Jayanta Samanta ${ }^{1}$ Jahnvi Dhar ${ }^{1}$ Abdul Khaliq ${ }^{2}$ Rakesh Kochhar ${ }^{1}$ \\ ${ }^{1}$ Department of Gastroenterology, Postgraduate Institute of \\ Medical Education \& Research, Chandigarh, India \\ 2Department of Gastroenterology, Umdaa Health Care, Hyderabad, \\ Telangana, India

\begin{abstract}
Address for correspondence Rakesh Kochhar, MD, DM, Department of Gastroenterology, Postgraduate Institute of Medical Education \& Research, Chandigarh, Sector 12, Chandigarh 160012, India (e-mail: dr_kochhar@hotmail.com).
\end{abstract}

\begin{abstract}
Keywords

- SARS-CoV-2

- COVID-19

- gastrointestinal symptoms

- coronavirus

- fecal shedding

- digestive symptoms

- feco-oral transmission

The world is witnessing a major public health crisis in the wake of the third coronavirus strain pandemic, a novel coronavirus (severe acute respiratory syndrome coronavirus 2). Although initially thought to be a pure respiratory pathogen, recent reports have highlighted not only the extrapulmonary effects of the virus but also, importantly, the gastrointestinal tract (GIT) effects. Various studies have looked into the effects of this novel coronavirus infection (coronavirus-19 disease [COVID-19]) on GIT involvement with reports of more frequent involvement than previously expected. With feco-oral transmission, debate being conclusively proven with fecal samples testing positive for COVID-19 and longer shedding time, it only underlines the importance of GIT involvement. Moreover, the presence of other GI diseases, such as inflammatory bowel disease, with COVID-19 infection might wreak havoc leading to poor patient outcomes.
\end{abstract}

\section{Introduction}

The modern world is facing a major public health crisis due to novel corona virus (severe acute respiratory syndrome coronavirus 2 [SARS-CoV-2]) which has caused a pandemic involving at least 210 countries. As we write, more than 3 million people have already been infected and more than 200,000 deaths have been reported and this is just the fourth month since the initial cases were detected in the Wuhan city of China in December 2019. ${ }^{1}$ Just like its close kin, severe acute respiratory syndrome coronavirus (SARS-CoV) and Middle East respiratory syndrome coronavirus (MERS-CoV), SARS-CoV-2 was primarily noted as a respiratory pathogen spreading via droplets and aerosols. The extrapulmonary effects and modes of transmission gained attention when the first confirmed case of SARS-CoV-2 reported from the United States had gastrointestinal (GI) complaints of nausea and vomiting followed later by diarrhea and patient's fecal specimen tested positive on day 7 of illness. ${ }^{2}$ Initial studies reported lower rates of GI symptoms such as diarrhea of 1 to $3.8 \% .^{3-6}$ However, with increased emphasis on reporting, this went up to as high as $61.1 \%$ in some reports with even pure GI manifestations without respiratory symptoms. ${ }^{7,8}$

With a flurry of data coming every day on various aspects of this novel infection, it becomes difficult to assimilate the information. Moreover, multiple societies have come up with multiple guidelines regarding this, and hence can be confusing for a practicing gastroenterologist. This review aims to comprehensively outline the GI manifestations of this virus, its potential to spread via the feco-oral route and its implications and an overview of management strategies for other GI diseases, such as inflammatory bowel disease (IBD) coexisting with coronavirus-19 disease (COVID-19) infection.

\section{The Pathogen and Current Status}

The SARS-CoV-2 is a zoonotic, enveloped, single-stranded RNA beta corona virus. It is related to viruses which caused previous epidemics such as SARS in 2002 and MERS in 2012. The genome is related more closely to the corona virus of bats. Although initially linked to exposure to the seafood market in Wuhan, China, its eventual evident person-to-person transmission has led to the spread of the disease. ${ }^{9,10}$ Designated 
as SARS-CoV-2 by the International Committee on Taxonomy of Viruses, it was later rechristened as COVID-19 by World Health Organization. ${ }^{5}$

This SARS-CoV-2 virus primarily transmits through fomites, air droplets, and aerosols from human to human. The receptor for attachment of this virus is angiotensinconverting enzyme 2 (ACE-2) which is present significantly in type- 2 alveolar cells in the lungs. Once attached to the spike protein $(\mathrm{S})$, the viral genome enters the cells, uses human cell machinery, and produces multiple viral particles to be released to infect other cells. To contain the virus, the immune mechanism steps in and a disproportionate immune response leads to flooding of the alveoli with fluid and damaging the epithelium of the alveoli hampering oxygen exchange resulting in acute respiratory distress syndrome (ARDS), multiorgan failure, and death. $4,5,11,12$

A large epidemiological data of 72,314 cases from China ${ }^{13}$ showed an overall case-fatality rate of $2.3 \%$. Among them, $3.8 \%$ affected were health care workers. COVID-19 has already exceeded the morbidity and mortality of previous coronavirus outbreaks and looking at this rate, it would soon match the cataclysmic proportions of the Spanish flu of 1918.

\section{Classical Symptoms}

The main symptomatology of COVID-19 pertains to respiratory system, with patients presenting predominantly with fever, cough, sore throat, and shortness of breath, and in serious cases, leading to ARDS, necessitating intensive care unit (ICU) admission, and sometimes death. ${ }^{5}$ At the outset, respiratory signs and symptoms were being documented and established diagnosis through nasopharyngeal swabs by reverse transcription polymerase chain reaction for SARSCoV-2. With passing time and aggrandized focus on GI symptomatology, more and more evidences are forthcoming on the GI involvement by the virus. Although liver involvement is noted too, the topic of hepatic manifestations and disease is beyond the scope of this article.

\section{Gastrointestinal Involvement}

Gastrointestinal tract (GIT) involvement has been well documented by previous corona viral infections both in animals and human beings. Diarrhea was seen to the tune of $10.6 \%$ with SARS and 30\% with MERS. ${ }^{9,14}$ Although earlier reports of COVID-19 reported a low 1 to $3.8 \%^{3-5}$ prevalence of diarrhea, these figures kept on surging as more focused GI symptomatology-related studies came to forefront.

\section{Pathophysiology}

The key step of the virus entry into the host cell is via the ACE-2 receptors, ${ }^{12,15,16}$ and ACE-2 is an important regulator of intestinal inflammation. ${ }^{17}$ Besides the presence of ACE-2 receptor, successful virus entry requires transmembrane protease serine 2 (TMPRSS2) which cleaves the S-protein of SARS-CoV-2 on the cell membrane and enables viral fusion. ${ }^{18}$ ACE-2 and TMPRSS2 were found not only in the lung alveolar cells and esophageal epithelial cells but also in the absorptive enterocytes of ileum and colon with interestingly higher expression. ${ }^{19}$ Using single-cell RNA sequencing, Liang et al demonstrated that ACE-2 was highly expressed in the proximal and distal intestine. ${ }^{20}$ Thus, the greater invasive nature of the virus and the abundance of its attaching receptors along the GIT can explain its GI manifestations. Both biopsy of small intestine and rectal swabs have been detected to be positive for SARS-CoV-2 virus. ${ }^{21}$

The mechanisms postulated for causation of diarrhea in COVID-19 infection are: (1) direct virus entry through ACE-2 receptor causing malabsorption, unbalanced intestinal secretion, and activated enteric nervous system; (2) direct/indirect damage to the intestinal epithelium by inflammatory response $^{22}$; (3) antibiotic and/or antiviral drugs-induced intestinal dysbiosis; (4) virus-induced disorders of the intestinal flora ${ }^{23}$; (5) "gut-lung axis" disturbances wherein respiratory flora alteration affects the digestive system by immune regulation. ${ }^{24}$

The evidence of shedding of the virus through feces is another definitive proof of GI involvement and a potential route for transmission.

\section{Symptomatology}

The commonly encountered GI symptoms include diarrhea, nausea, vomiting, abdominal pain, and anorexia. Different studies have reported GI symptoms with varying frequencies. A large study of 1,099 patients had nausea in 5\% and diarrhea in $3.8 \%$ of cases, ${ }^{3}$ while the latest data from Wuhan reported a staggering $79 \%$ of the patient with GI symptoms. ${ }^{25}$ Jin et al, in their study of 74 patients of COVID-19 cases with GI symptoms, interestingly pointed out that $28 \%$ of these cases had no respiratory symptoms. ${ }^{8}$ Similarly, An et al reported 9 patients presenting only with digestive symptoms at the onset. ${ }^{26}$ This underlines the fact that pure GI form of COVID-19 infection, although less common, can exist and confuse the clinical scenario. This can be a red flag sign for the gastroenterologist to ensure better self-protection from possible infection. Lin et al reported $61.1 \%$ GI symptoms with $24.2 \%$ diarrhea and $17.9 \%$ nausea. ${ }^{7}$ On endoscopy in six of these cases, two severely diseased cases showed evidence of virus in esophagus, stomach, duodenum, and rectum proving that the virus can thrive all along the GIT. ${ }^{7}$ A synopsis of the various GI symptoms and their reported frequencies is given in $\boldsymbol{- T a b l e} \mathbf{1}$.

Diarrhea might sometimes be the presenting symptom. In fact, Fang et al found that $22.2 \%$ of the patients having diarrhea presented with it before the diagnosis of COVID-19.25 Diarrhea usually occurred 1 to 8 days from the onset with a

Table 1 Gl symptoms in COVID-19 infection

\begin{tabular}{|l|l|}
\hline Symptoms & Involvement (\%) \\
\hline Anorexia & $39.9-78.6$ \\
\hline Diarrhea & $2-49.5$ \\
\hline Nausea & $1-29.4$ \\
\hline Vomiting & $3.6-15.9$ \\
\hline Abdominal pain & $2.2-6.0$ \\
\hline Gastrointestinal bleeding & $4-13.7$ \\
\hline Loss of taste & $5.6-88$ \\
\hline
\end{tabular}

Abbreviations: COVID-19, coronavirus-19 disease; Gl, gastrointestinal. 
mean duration of $4.1 \pm 2.5$ days (range: $1-14$ days). The frequency has been reported to be $3.3 \pm 1.6 /$ day ${ }^{25}$ Anorexia is much more commonly reported than other symptoms, but since it is difficult to objectively assess it, the most common definitive GI symptom would be diarrhea.

The correlation between severity of disease and GI symptoms is dubious. Some studies such as those by Fang et $\mathrm{al}^{25}$ and Guan et $\mathrm{al}^{3}$ found no difference in the digestive symptom rates between the critically ill and the nonsevere cases. On the contrary, Wang et $\mathrm{al}^{27}$ recorded higher rates of GI symptoms among ICU patients (anorexia 66.7\% vs. $30.4 \%$; abdominal pain $8.3 \%$ vs. $0 \%$ ) compared with the less severe cases. A recent pooled data analysis interestingly found that increased COVID-19 severity was associated with abdominal pain but not for diarrhea. ${ }^{28}$ Children exhibited similar rates of diarrhea (9.6-15\%), but had higher rates of vomiting. ${ }^{29,30}$

\section{Fecal Shedding: Hard Evidence of GI Involvement}

SARS-CoV-2 has exhibited GI tropism akin to its close relatives, SARS-CoV which had virus detected in biopsy and fecal specimens. ${ }^{14}$ In fact, the first case reported from the United States had fecal test positive at day 7 of illness. ${ }^{2}$ In one of the earlier studies, Chen et $\mathrm{al}^{31}$ found that 28 of 42 patients tested positive for SARS-CoV-2 RNA in stool specimens. Of them, 18 (64.29\%) patients remained positive for viral RNA in feces for a mean period of 7 days even after pharyngeal swabs turned negative. Overall, the proportion of patients with stool positivity has ranged between $36 \%$ and 53\%. ${ }^{23,32}$ Positivity did not correlate with disease activity or digestive symptoms. The fecal test became positive around 2 to 5 days after the oropharyngeal swab positivity and lasted for 1 to 16 days. ${ }^{32,33}$ The most ruffling data, however, is the fact that 23 to $82 \% 4,23,33$ of the patients continue to show fecal positivity for a mean period of 11 days after the respiratory specimens have turned negative. ${ }^{34}$ Moreover, only half of these fecal positive cases actually had diarrhea. ${ }^{35}$ This raises a question about discharging a patient based on negative respiratory sample only.

The above facts clearly depict that the GIT acts as a potent source of viral shedding with no correlation with clinical symptomatology, making it incalculable to label a person safe from infective potential. Moreover, the virus has been shown to remain viable in aerosol form for 3 hours and close to 72 hours on plastic and stainless steel surfaces..$^{36}$ In a proof of concept study, samples collected from the surface of the toilet bowl, sink bowl, and door handle of the bathroom used by a fecal positive patient turned out to be positive before cleaning, underscoring the significance of hygiene maintenance. ${ }^{37}$ This feco-oral or "fecomucosal" route of transmission has profound implication on the strategies needed to control the spread of the disease. The high viral load in the stool, its stability on regular surfaces, and generation of toilet fumes ${ }^{38}$ make the virus a formidable agent for human-to-human spread.

\section{COVID Infection Concomitant with Other GI Conditions}

Pre-existing conditions such as IBD or other conditions may predispose the individual to more severe disease if they happen to contract COVID infection. The underlying disease might flare up due to the super added infection or the COVID-19 infection might become severe because of poor baseline immune function. Hence, these groups of patients need special mention.

\section{Inflammatory Bowel Disease}

Data are not adequate yet to prove or disprove the theory of whether IBD patients are at an increased risk of infection in this COVID-19 era. However, theoretically, IBD portends an enhanced risk of infection by two mechanisms: (1) the virus receptor, ACE-2, has increased tissue concentration in the inflamed mucosa of active ulcerative colitis and Crohn's disease patients. ${ }^{39}$ Moreover, the serine protease level, the key primer to activate S-protein is 10 times higher in patients with IBD than others. ${ }^{40}$ Both these factors contribute to enhanced viral attachment to the host cell and thus, increased infection and (2) IBD patients who are already on immunosuppressive medications may be at a higher risk of infection. In fact, active disease with thiopurines has been shown to increase the infection potential. ${ }^{41}$ Of late, International Organization for the Study of Inflammatory Bowel Diseases (IOIBD) opined that vedolizumab and ustekinumab do not increase infection risk, while thiopurines, antitumor necrosis factor agents, and tofacitinib might pose debatable risk. ${ }^{42}$

Another factor due to the COVID-19 effect is the lack of the regular OPD services. Impaired compliance with discontinuation of medications has led to reports of disease exacerbation. This is more likely to happen in India, wherein majority of the patients hail from poor socioeconomic background with lack of proper awareness or social support. In a questionnaire survey by Bai et al, ${ }^{43}$ among 123 IBD cases, 18 (14.4\%) had exacerbation and $70.4 \%$ stated that COVID-19 impacted their scheduled follow-up. Probably, the advocacy of the facilities of "tele-medicine" would be able to untangle a part of this complex sociomedical issue. Thus, with inadequate data of increased risk for IBD subgroup, ${ }^{42}$ longer clearance time for certain drugs, such as thiopurine, ${ }^{44}$ increased risk of disease flare on stopping IBD medications ${ }^{45}$ and poor hospital/clinic backup for chronic cases, ${ }^{46}$ it is tricky to ensure best management for active disease. Real-world data on the actual outcome of patients with IBD and COVID-19 infection are lacking. An international registry (SECURE-IBD) ${ }^{47}$ has been formulated for this purpose, and as of now, the initial data show that of the 580 patients registered, 70\% were treated on OPD basis, while $30 \%$ required hospitalization and $5 \%$ required ventilator support with $3 \%$ mortality. Thus, not only the infection rate but also the severity is similar for IBD cases compared with non-IBD. ${ }^{48}$

Multiple societies have come up with guidelines for the management of IBD during this COVID-19 pandemic. A composite synopsis of the recommendations of most of the guidelines (AGA American Gastroenterology Association clinical practice update, ${ }^{49}$ IOIBD, ${ }^{42}$ ECCO European Crohn's 
and Colitis Organisation Task Force, ${ }^{50}$ BSG British Society Guidelines expanded consensus, ${ }^{51}$ Crohn's and Colitis Foundation ${ }^{52}$ ) is as follows: (1) the high-risk group encompasses elderly ( $>65$ years) patients, with comorbidities, pregnancy and patients on immunomodulator therapy, biologicals, and high-dose steroids (>20 mg/d), (2) protective measures to be followed include the general instructions such as use of face masks ( N95 masks), hand hygiene, and social distancing, (3) patients on 5-aminosalicylic acid (5-ASA) should continue their medication, (4) steroids to continue at the same dose; no dose reduction advised, (5) thiopurines: to continue if already on them, (6) biologicals to continue including infusions, provided the treating center has SARS-CoV-2 screening protocol; monotherapy preferred over combination with immunomodulators; switching not recommended, (7) JAK inhibitors to continue if already taking, (8) for clinical trials: to continue therapies until tested positive for SARS-CoV-2, (9) patients tested positive for SARS-CoV-2 but asymptomatic: reduce the dose of steroids ( $<20 \mathrm{mg} / \mathrm{d})$ or switch to budesonide; stop thiopurines, methotrexate, tofacitinib; delay dosing of monoclonal for 2 weeks while monitoring for COVID-19, (10) patients having COVID-19: 5-ASA and local therapy, dietary management to continue oral budesonide may be continued; other medications to be stopped, and (11) restart medications after 2 weeks if the patient does not develop COVID symptoms or symptoms resolve.

For children, the guidelines are different. COVID-19 and IBD behave in opposite ways in children compared with adults. While the course of IBD tends to be severe in children compared with adults, COVID-19 infection tends to run a milder course. Hence, European Society for Paediatric Gastroenterology Hepatology and Nutrition guidelines clearly states that no dose reduction of any medications for IBD treatment in children is needed..$^{53}$

\section{Effects on the Pancreas}

In a study of 52 cases of COVID-19 pneumonia, 17\% had pancreatic injury ${ }^{54}$ and it was associated with higher incidence of anorexia and diarrhea and more severe illness on admission. Three possible explanations include: ACE- 2 receptors on pancreatic islets causing acute diabetes, cytokine storm, and drug-induced pancreatic injury.

\section{GI Side Effects of Drugs Used Tried for COVID-19 Treatment}

A host of drugs has been tried for the treatment of COVID-19 including antiviral and antimalarial and antihelminthic drugs. The efficacy of these drugs is yet to be established, but these drugs can themselves cause GI side effects which the in-hospital patient might experience. A brief outline of the drugs and their commonly reported GI side effects are given in - Table 2 .

\section{Management of the GI symptoms}

Management of the GI symptoms entails routine management as for any other diseases. Diarrhea is usually self-limiting and can be either viral, immune, antibiotic associated or due to

Table 2 Drugs used for treatment of COVID-19 and their GI side effects

\begin{tabular}{|c|c|c|c|}
\hline $\begin{array}{l}\text { COVID-19 } \\
\text { treatments }\end{array}$ & $\begin{array}{l}\text { Dose for COVID-19 } \\
\text { infection }\end{array}$ & Dosing route & GI/liver-related side effects \\
\hline Remdesivir & $\begin{array}{l}200 \mathrm{mg} \text { single dose followed } \\
\text { by } 100 \mathrm{mg} \text { OD for } 10 \mathrm{~d}\end{array}$ & Intravenous & Nausea, vomiting, deranged liver enzymes \\
\hline Hydroxychloroquine & $\begin{array}{l}1,200 / 800 \mathrm{mg} \text { loading on day } \\
1 \text { followed by } 400 \mathrm{mg} \text { daily }\end{array}$ & Oral & Nausea, vomiting, weight loss, abdominal pain \\
\hline Chloroquine & $500 \mathrm{mg} \mathrm{BD}$ & Oral & $\begin{array}{l}\text { Increased liver enzymes, anorexia, nausea, vomiting, diar- } \\
\text { rhea, abdominal cramps }\end{array}$ \\
\hline Azithromycin & $500 \mathrm{mg}$ OD & Oral & Diarrhea, nausea/vomiting, pain abdomen \\
\hline Tocilizumab & $\begin{array}{l}8 \mathrm{mg} / \mathrm{kg} \text { IV once (can com- } \\
\text { bine with steroids); max. } 3 \\
\text { doses }\end{array}$ & Intravenous & $\begin{array}{l}\text { Elevated liver enzymes, bowel perforation, pancreatitis, } \\
\text { abdominal pain, reactivation of chronic hepatitis B }\end{array}$ \\
\hline lopinavir/ritonavir & $400 \mathrm{mg} / 100 \mathrm{mg} B D$ & Oral & $\begin{array}{l}\text { Deranged liver enzymes; in few cases, jaundice reported in } \\
\text { HIV infected people }\end{array}$ \\
\hline Favipiravir & $\begin{array}{l}1,000-1,600 \mathrm{mg} \text { on the first } \\
\text { day, followed by } 400-800 \mathrm{mg} \\
\text { BD for } 4-13 \mathrm{~d}\end{array}$ & Oral & Nil \\
\hline Ivermectin & $\begin{array}{l}200 \mu \mathrm{g} / \mathrm{kg} \text { of body weight } \\
\text { taken as one dose }\end{array}$ & Oral & $\begin{array}{l}\text { Nausea, vomiting, diarrhea (very few reports on elevated } \\
\text { liver enzymes or jaundice: uncommon) }\end{array}$ \\
\hline Sarilumab & NA & Intravenous & Increased ALT; few cases of GI perforation \\
\hline Corticosteroids & $\begin{array}{l}\text { Pulse therapy (dose variable } \\
500 \mathrm{mg} / 1 \mathrm{~g} \text { ) }\end{array}$ & Intravenous/oral & $\begin{array}{l}\text { Immunosuppression leading to increased infections/reacti- } \\
\text { vations of underlying latent infection, bowel perforation }\end{array}$ \\
\hline Baricitinib & $2 \mathrm{mg}$ OD & Oral & $\begin{array}{l}\text { Bowel perforation, hepatitis B reactivation, nausea, } \\
\text { vomiting }\end{array}$ \\
\hline
\end{tabular}

Abbreviations: ALT, alanine aminotransferase; COVID-19, coronavirus-19 disease; GI, gastrointestinal; IV, intravenous; NA, not available. 
dysbiosis. Proper hydration is essential to maintain electrolyte balance. The use of routine antidiarrheal agents such as loperamide can be done to mitigate the symptoms. Probiotics can be prescribed for dysbiosis and antispasmodics can be added for abdominal pain. Abdominal pain can be disease related or maybe due to other causes and needs to be evaluated, if primary symptomatic treatment does not suffice.

\section{Prevention of Feco-oral Transmission}

GI involvement with fecal shedding highlights the necessity of preventing the feco-oral route of transmission to curb its spread. In a developing country like India and as gastroenterologists, this encompasses adoption of the conventional strategies of hygiene awareness that we are so familiar with since ages. The conventional five " $F$ " factors for feco-oral transmission are the fingers, flies, fields, fluids, and food. Raising public awareness for better hygiene, safe food practices, forbidding open defecation, and ensuring clean water practices are the foundation stones for preventing the spread of this disease and need to be rigorously implemented.

\section{Conclusion}

GI manifestations are not uncommon in patients with COVID-19 infection and with passage of time they are more frequently being reported. In fact, a subgroup of these cases might present with pure GI symptoms. Fecal shedding of the virus and its detection not only establishes the GIT involvement by the virus but also highlights a potential source of spread-feco-oral transmission. More data are needed to come to concrete management decisions on difficult situations such as IBD with COVID infection. During this time of coronavirus pandemic, as more and more data and evidences keep pouring in, we, gastroenterologists, have to unlearn many older habits and learn a few new ones to protect ourselves and our patients. The principle should be "primum non nocere"-do no harm. Catching up with the vast knowledge that pours in everyday about this virus and management protocols, we have to tread our path more carefully.

\section{Conflict of Interest}

None declared.

\section{References}

1 WHO. Coronavirus disease 2019 (COVID-19) Situation Report - 90. May 1, 2020. Available at: https://www.who.int/docs/ default-source/coronaviruse/situation-reports/20200419-sit rep-90-covid-19.pdf?sfvrsn=551d47fd_2

2 Holshue ML, DeBolt C, Lindquist S, et al; Washington State 2019-nCoV Case Investigation Team. First case of 2019 novel coronavirus in the United States. N Engl J Med 2020;382(10):929-936

3 Guan WJ, Ni ZY, Hu Y, et al; China Medical Treatment Expert Group for COVID-19. Clinical characteristics of coronavirus disease 2019 in China. N Engl J Med 2020;doi:10.1056/ NEJMoa2002032

4 Zhu N, Zhang D, Wang W, et al; China Novel Coronavirus Investigating and Research Team. A novel coronavirus from patients with pneumonia in China, 2019. N Engl J Med 2020;382(8):727-733

5 Huang C, Wang Y, Li X, et al. Clinical features of patients infected with 2019 novel coronavirus in Wuhan, China. Lancet 2020;395(10223):497-506

6 Chen N, Zhou M, Dong X, et al. Epidemiological and clinical characteristics of 99 cases of 2019 novel coronavirus pneumonia in Wuhan, China: a descriptive study. Lancet 2020;395(10223):507-513

7 Lin L, Jiang X, Zhang Z, et al. Gastrointestinal symptoms of 95 cases with SARS-CoV-2 infection. Gut 2020; gutjnl-2020-321013; doi:10.1136/gutjnl-2020-321013

8 Jin X, Lian JS, Hu JH, et al. Epidemiological, clinical and virological characteristics of 74 cases of coronavirus-infected disease 2019 (COVID-19) with gastrointestinal symptoms. Gut 2020; gutjnl-2020-320926;doi:10.1136/gutjnl-2020-320926

9 Chan JF, Yuan S, Kok KH, et al. A familial cluster of pneumonia associated with the 2019 novel coronavirus indicating person-to-person transmission: a study of a family cluster. Lancet 2020;395(10223):514-523

10 Phan LT, Nguyen TV, Luong QC, et al. Importation and humanto-human transmission of a novel coronavirus in Vietnam. $\mathrm{N}$ Engl J Med 2020;382(9):872-874

11 Yin Y, Wunderink RG. MERS, SARS and other coronaviruses as causes of pneumonia. Respirology 2018;23(2):130-137

12 Zhou P, Yang XL, Wang XG, et al. A pneumonia outbreak associated with a new coronavirus of probable bat origin. Nature 2020;579(7798) :270-273

13 Novel Coronavirus Pneumonia Emergency Response Epidemiology Team. [The epidemiological characteristics of an outbreak of 2019 novel coronavirus diseases (COVID-19) in China].Zhonghua Liu Xing Bing Xue Za Zhi 2020;41(2):145-151

14 Leung WK, To KF, Chan PK, et al. Enteric involvement of severe acute respiratory syndrome-associated coronavirus infection. Gastroenterology 2003;125(4):1011-1017

15 Wan Y, Shang J, Graham R, Baric RS, Li F. Receptor recognition by the novel coronavirus from Wuhan: an analysis based on decade-long structural studies of SARS coronavirus. J Virol 2020;94(7):e00127-20

16 Wan Y, Shang J, Sun S, et al. Molecular mechanism for antibody-dependent enhancement of coronavirus entry. J Virol 2020;94(5):e02015-19

17 Hashimoto T, Perlot T, Rehman A, et al. ACE2 links amino acid malnutrition to microbial ecology and intestinal inflammation. Nature 2012;487(7408):477-481

18 Hoffmann M, Kleine-Weber H, Schroeder S, et al. SARS-CoV-2 cell entry depends on ACE2 and TMPRSS2 and is blocked by a clinically proven protease inhibitor. Cell 2020;181(2):271-280.e8

19 Zhang H, Kang Z, Gong H, et al. Digestive system is a potential route of COVID-19: an analysis of single-cell coexpression pattern of key proteins in viral entry process. Gut 2020; doi:10.1136/gutjnl-2020-320953

20 Liang W, Feng Z, Rao S, et al. Diarrhoea may be underestimated: a missing link in 2019 novel coronavirus. Gut 2020; gutjnl-2020-320832doi:10.1136/gutjnl-2020-320832

21 Xu Y, Li X, Zhu B, et al. Characteristics of pediatric SARS-CoV-2 infection and potential evidence for persistent fecal viral shedding. Nat Med 2020;26(4):502-505

22 Xie C, Jiang L, Huang G, et al. Comparison of different samples for 2019 novel coronavirus detection by nucleic acid amplification tests. Int J Infect Dis 2020;93:264-267

23 Xiao F, Tang M, Zheng X, Liu Y, Li X, Shan H. Evidence for gastrointestinal infection of SARS-CoV-2. Gastroenterology 2020; S0016-5085(20)30282-1doi:10.1053/j.gastro.2020.02.055

24 Budden KF, Gellatly SL, Wood DL, et al. Emerging pathogenic links between microbiota and the gut-lung axis. Nat Rev Microbiol 2017;15(1):55-63 
25 Fang D, Ma J, Guan J, Wang M, Song Y, Tian D. Manifestations of digestive system in hospitalized patients with novel coronavirus pneumonia in Wuhan, China: a single-center, descriptive study. Chin J Dig 2020;40

26 An P, Chen H, Jiang X, Su J, Xiao Y, Ding Y, et al. Clinical features of 2019 novel coronavirus pneumonia presented gastrointestinal symptoms but without fever onset. 2020

27 Wang D, Hu B, Hu C, et al. Clinical characteristics of 138 hospitalized patients with 2019 novel coronavirus-infected pneumonia in Wuhan, China. JAMA 2020;doi:10.1001/ jama.2020.1585

28 Henry BM, de Oliveira MHS, Benoit J, Lippi G. Gastrointestinal symptoms associated with severity of coronavirus disease 2019 (COVID-19): a pooled analysis. Intern Emerg Med 2020; doi:10.1007/s11739-020-02329-9

29 Liu W, Zhang Q, Chen J, et al. Detection of covid-19 in children in early January 2020 in Wuhan, China. N Engl J Med 2020;382(14):1370-1371

30 Xia W, Shao J, Guo Y, Peng X, Li Z, Hu D. Clinical and CT features in pediatric patients with COVID-19 infection: different points from adults. Pediatr Pulmonol 2020;55(5):1169-1174

31 Chen Y, Chen L, Deng Q, et al. The presence of SARS-CoV-2 RNA in feces of COVID-19 patients. J Med Virol 2020;doi:10.1002/ jmv. 25825

32 Zhang J, Wang S, Xue Y. Fecal specimen diagnosis 2019 novel coronavirus-infected pneumonia. J Med Virol 2020;doi:10.1002/jmv.25742

33 Ling Y, Xu SB, Lin YX, et al. Persistence and clearance of viral RNA in 2019 novel coronavirus disease rehabilitation patients. Chin Med J (Engl) 2020;doi:10.1097/CM9.0000000000000774

$34 \mathrm{Wu}$ Y, Guo C, Tang L, et al. Prolonged presence of SARS-CoV-2 viral RNA in faecal samples. Lancet Gastroenterol Hepatol 2020;5(5):434-435

35 Ong J, Young BE, Ong S. COVID-19 in gastroenterology: a clinical perspective. Gut 2020; gutjnl-2020-321051doi:10.1136/ gutjnl-2020-321051

36 van Doremalen N, Bushmaker T, Morris DH, et al. Aerosol and surface stability of SARS-CoV-2 as compared with SARSCoV-1. N Engl J Med 2020;382(16):1564-1567

37 Ong SWX, Tan YK, Chia PY, et al. Air, surface environmental, and personal protective equipment contamination by severe acute respiratory syndrome coronavirus 2 (SARS-CoV-2) from a symptomatic patient. JAMA 2020;doi:10.1001/jama.2020.3227

38 Yu IT, Li Y, Wong TW, et al. Evidence of airborne transmission of the severe acute respiratory syndrome virus. N Engl J Med 2004;350(17):1731-1739

39 Garg M, Royce SG, Tikellis C, et al. Imbalance of the renin-angiotensin system may contribute to inflammation and fibrosis in IBD: a novel therapeutic target? Gut 2020;69(5):841-851

40 Jablaoui A, Kriaa A, Mkaouar H, et al. Fecal serine protease profiling in inflammatory bowel diseases. Front Cell Infect Microbiol 2020;10:21

41 Wisniewski A, Kirchgesner J, Seksik P, et al. Saint-Antoine IBD network. Increased incidence of systemic serious viral infections in patients with inflammatory bowel disease associates with active disease and use of thiopurines. United European Gastroenterol J 2019; doi:10.1177/2050640619889763

42 IOIBD. IOIBD Update on COVID19 for Patients with Crohn's Disease and Ulcerative Colitis. April 13, 2020. Available at: https://www.ioibd.org/ioibd-update-on-covid19-for-patients-with-crohns-disease-and-ulcerative-colitis

43 Bai X, Yang H, Qian J. COVID-19 outbreak and inflammatory bowel disease management: a questionnaire survey from realistic practice. J Crohn's Colitis 2020; jjaa064doi:10.1093/ ecco-jcc/jjaa064

44 Danese S, Cecconi M, Spinelli A. Management of IBD during the COVID-19 outbreak: resetting clinical priorities. Nat Rev Gastroenterol Hepatol 2020;doi:10.1038/s41575-020-0294-8

45 Boyapati RK, Torres J, Palmela C, et al. Withdrawal of immunosuppressant or biologic therapy for patients with quiescent Crohn's disease. Cochrane Database Syst Rev 2018;5:CD012540

46 Rosenbaum L. Facing COVID-19 in Italy - ethics, logistics, and therapeutics on the epidemic's front line. N Engl J Med 2020;doi:10.1056/NEJMp2005492

47 SECURE-IBD. Surveillance Epidemiology of Coronavirus (COVID-19) Under Research Exclusion in Inflammatory Bowel Disease (SECURE-IBD). April 17, 2020. Available at: https:// covidibd.org/current-data

48 Higgins PDR, Ng S, Danese S, Rao K. The risk of SARS-CoV-2 in immunosuppressed IBD patients. Crohn's Colitis 360 2020;2(2):doi:10.1093/crocol/otaa026

49 Rubin DT, Feuerstein JD, Wang AY, Cohen RD. AGA clinical practice update on management of inflammatory bowel disease during the COVID-19 Pandemic: expert commentary. Gastroenterology 2020;:S0016-5085(20)30482-0doi:10.1053/j. gastro.2020.04.012

50 ECCO. 1st Interview COVID-19 ECCO Taskforce. April 13, 2020. Available at: https://www.ecco-ibd.eu/images/6_ Publication/6_8_Surveys/1st_interview_COVID-19\%20 ECCOTaskforce_published.pdf

51 BSG. BSG expanded consensus advice for the management of IBD during the COVID-19 pandemic. April 6, 2020. Available at: https://www.bsg.org.uk/covid-19-advice/bsg-advice-formanagement-of-inflammatory-bowel-diseases-during-thecovid-19-pandemic

52 Foundation Csa C. Resources for IBD Healthcare Professionals 2019 Novel Coronavirus (COVID-19). April 6, 2020. Available at: https://www.crohnscolitisfoundation.org/coronavirus/ professional-resources

53 Turner D, Huang Y, Martín-de-Carpi J, et al; Paediatric IBD Porto group of ESPGHAN. COVID-19 and paediatric inflammatory bowel diseases: global experience and provisional guidance (March 2020) from the Paediatric IBD Porto group of ESPGHAN. J Pediatr Gastroenterol Nutr 2020

54 Wang F, Wang H, Fan J, Zhang Y, Wang H, Zhao Q. Pancreatic injury patterns in patients with COVID-19 pneumonia. Gastroenterology 2020; S0016-5085(20)30409-1doi:10.1053/j. gastro.2020.03.055 